\title{
Investigation on the performance of Cedrus deodara seedlings artificially inoculated with the mycorrhizal associate Rhizopogon himalayensis
}

\author{
Lal Singh ${ }^{1}$,Ashwani Tapwal ${ }^{2}$, J.S. Thakur ${ }^{3}$ and T.N. Lakhanpal ${ }^{4 *}$ \\ ${ }^{\prime}$ Himalayan Research Group, Chotta Shimla, H.P. -171002 \\ ${ }^{2}$ Himalayan Forest Research Institute, Shimla-171013 \\ ${ }^{3 .}$ Govt. College Banjar, Kullu, H.P. 175123 \\ ${ }^{4}$ Dept-. of Biosciences, Himachal Pradesh Univ., Shimla-171005 \\ "Corresponding authorEmail: tezlakhanpal@rediffmail.com \\ (Submitted on May 25, 2020; Accepted on October 10, 2020)
}

\section{ABSTRACT}

Performance of the seedlings of Cedrus deodara artificially inoculated with Rhizopogon himalayensis was evaluated in three sets of soils viz.: forest soil, wasteland soil, and mixed soil. It was observed that the growth and development of inoculated and uninoculated seedlings were almost similar till the age of $2 \frac{1}{2}$ months except that the seedling height and root length were significantly higher in the inoculated seedlings. The inoculated seedlings attained a height of $25-30 \mathrm{~cm}$ within 6 months whereas the seedlings with natural inoculum attained the same in $18-24$ months, exhibiting an incredibly significant difference. Similarly, the inoculated seedlings excelled the seedlings with natural inoculum in collar diameter, fresh and dry weight of shoot and root. Concerning soils, the wasteland soil when used in mixture with natural zone soil produced better seedlings with quality growth characteristics. Therefore, it can be concluded that seedlings inoculated with $R$. himalayensis performed better in growth and development than those with natural inoculum.

Keywords: Rhizopogon himalayensis, Trappeindia himalayensis, Cedrus deodara, mycorrhiza, artificial inoculation, N.W. Himalaya.

\section{INTRODUCTION}

It is well established that mycorrhizal colonization enhances the seedling establishment and survival (Dickie et al., 2002; Kumar and Atri, 2017). Researchers have discussed from time to time different inoculation methods and types of inocula for nursery practices (Molina, 1977; Trappe, 1977; Marx, 1980; Marx et al., 1991; Rincon et al., 2001; Kaewgrajang et al., 2019). Cedrus deodara (Roxb. ex D. Don) G. Don is an economically important tree of North West Himalaya. It shows extremely poor regeneration and growth in nature. Rhizopogon himalayensis (Castellano et al.) Mujic $\&$ Sm., a hypogeous edible fungus has been observed to form ectomycorrhiza with $C$. deodara. In vitro synthesis of mycorrhiza between $C$. deodara and $R$. himalayensis has been successfully achieved (Singh, 1992; Singh et al. 2020). Therefore, nursery trials of $C$. deodara were established by inoculating with $R$. himalayensis and the growth and development of the seedlings was recorded.

The use of pure mycelia cultures of ectomycorrhizal fungi is a biologically sound method of inoculation (Bowen, 1965; Mikola, 1970, 1973; Trappe, 1977). Originally developed by Moser (1958), it was later used in other countries to prove experimentally better field survival and growth of inoculated tree seedlings with specific ectomycorrhizae (Tackacs, 1967; Theodorou and Bowen, 1970; Vazzo and Hacskaylo, 1971). Hence the mycorrhizal inoculations improve the growth, survival, and establishment of seedling after out planting (Berry, 1982; Valdes, 1986; Marx and Cordell, 1989; Parladé et al., 2004; Holusa et al., 2015).

Mycorrhizal plants absorb many minerals from the soil much more efficiently than non-mycorrhizal plants (Hatch, 1937; Mejstrik, 1970; Bowen et al., 1974; Kumar and Atri, 2017;
Arteaga-León et al., 2018). Among the various major and minor elements, the uptake of phosphorus (P) has been documented substantially (Hatch, 1937; Melin, 1953; Harley, 1959). Mejstrick and Krause (1973) and Herrera et al. (1978) provided direct evidence for utilization of organic $\mathrm{P}$ sources using mycorrhizae by employing the radio transfer technique.

\section{MATERIAL AND METHODS}

Mass inoculum production: Fourteen ${ }^{* *}$ combinations of vermiculite and peat moss, saturated with Pridham Yeast Malt Dextrose Agar (PYMDA), and Melin Modified Norkrans medium (MMN) were used in test tubes to observe the colonization of mycobiont. Different substrate combinations were thoroughly mixed, autoclaved, and then inoculated with $8 \mathrm{~mm}$ culture disc and later incubated at $30^{\circ} \mathrm{C}$ for 10 days. In addition to the above, mass inoculum production was also tried on wheat grains following the method of Stoller (1962).

Seed sowing and artificial inoculation: Uniform seeds of $C$. deodara were collected from a healthy forest during OctoberNovember 1989. Two types of soils, i.e. forest soil (from the natural zone of $C$. deodara) and wasteland soil (degraded area) were used individually as well as in mixture $(1: 1 \mathrm{v} / \mathrm{v})$. The soils were sieved and fumigated with $2 \%$ formaldehyde. The polybags (9x5") were initially filled to $2 / 3$ of their filling capacity and the upper $1 / 3$ portion was then filled with autoclaved soil mixed with grain spawn in the ratio 1:10. Two surface sterilized seeds were sown in each polybag.

Observations on growth and development of seedlings: Three seedlings were randomly lifted from each soil treatment and the control set, every fortnight till three months for recording shoot height, root length, fresh weight of root and shoot, root collar diameter, total number of short roots, and number of mycorrhizal roots. Thereafter, observations

$* *$

1. Vermiculite (Pure), 2. Vermiculite (Pure) MMN, 3.Vermiculite (Pure) PDYDA, 4.Vermiculite (Pure)MMN+ PMYDA(1:1), 5. Peat Moss (Pure), 6 Peat Moss (Pure) MMN, 7. Peat Moss (Pure) PMYDA, 8. Pest Moss (Pure) MMN + PMYDA (1:1), 9. Vermiculite + Peat Moss (1:1), 10.Vermiculite + Peat Moss (1:1) MMN, 11. Vermiculite + Peat Moss (1:1) PYMDA, 12. Vermiculite + Peat Moss (1:1) MMN + PYMDA (1:1), 13. Vermiculite + Peat Moss (3/4:1/4) MMN + PYMDA(1:1), 14. Vermiculite + Peat Moss (1/4:3/4) MMN + PMYDA(1:1) 
were recorded at one-month interval till the seedlings attained the age of six months and final observations were recorded in one-year old seedlings.

Development of mycorrhiza: Morpho-anatomical details of mycorrhizae have been worked out according to Zak (1971). Mycorrhizal roots were fixed in Formalin Acetic Acid (FAA) ${ }^{* * * *}$ for 24 hours, then thoroughly rinsed in running water and preserved in $70 \%$ alcohol. Anatomical details were recorded by both hand and microtome sections (Johansen, 1940). The colour of the Hartig net and mantle was observed in unstained sections. For cellular details, the sections were stained in cotton blue and safranin-fast green combinations.

\section{RESULTS}

Mass inoculum production: The colonization pattern of the mycobiont revealed wheat grains to be the best substrate. In vermiculite peat moss mixture, the pure vermiculite saturated with PYMDA (Pridham Yeast Malt Dextrose Agar) solution supported less fungal growth, than wheat grains. Hence wheat grains were used for mass inoculum production. During mass culturing, the mycobiont completely colonized $100-200 \mathrm{~g}$ wheat grains in 15-18 days (Table-1).

Seed sowing and artificial inoculation: Artificial inoculation with mycobiont ensures mycorrhization of the root as soon as it emerges from the radicle. In the customary nursery practices, rhizosphere soil is used for raising deodar seedlings assuming that it contains propagules of some mycobiont. But in wasteland soil or in degraded lands possibility of the propagules of mycobiont is very remote, hence in such cases artificial inoculation becomes essential. Therefore, in the present study the two soil types, viz. wasteland soil and the forest soil and their mixture was used. Seed sowing and artificial inoculation were carried out in December.

Growth and development of inoculated and uninoculated seedlings: One-way analysis of variance (ANOVA) was performed for different samplings to test the significance between means of different parameters and treatments. The Fratios for different parameters in inoculated and uninoculated treatments in sampling done at 15 days, one month and twomonth intervals were non-significant. The F-ratios for different parameters at $2 \frac{1}{2}, 3,4,5,6$, and 12 months sampling stages were significant (Table-5). The growth and development of seedlings was recorded at 15 days, 1, 2, 21/2, 3, 4, 5, 6 and 12 months. However, observations for 3, 6, and 12 months are presented here.

Effect of mycorrhizal inoculations on seedling height: At three months sampling stage, the seedlings grown in inoculated mixture of soils attained maximum height (16.22 $\mathrm{cm})$ and least in uninoculated forest soil $(9.66 \mathrm{~cm})$. Similarly, at six months sampling stage, maximum seedling height was recorded in inoculated mixture of soils $(29.16 \mathrm{~cm})$ and least in uninoculated wasteland soil $(12.13 \mathrm{~cm})$. Likewise, maximum seedling height at one year was recorded in seedlings grown in an inoculated mixture of soils $(30.46 \mathrm{~cm})$ and least in
Table 1: Growth of Rhizopogon himalayensis on different substrate combinations

\begin{tabular}{lllll}
\hline $\begin{array}{l}\text { S. } \\
\text { No. }\end{array}$ & Substrate & $\begin{array}{l}\text { Substrate } \\
\text { ratio }\end{array}$ & Nutrient Medium & $\begin{array}{l}\text { Growth of } \\
\text { mycelium }\end{array}$ \\
\hline 1. & Vermiculite & Pure & --- & $-{ }^{*}$ \\
2. & Vermiculite & Pure & MMN & $+* *$ \\
3. & Vermiculite & Pure & PYMDA & +++++ \\
4. & Vermiculite & Pure & MMN+PYMDA & +++ \\
5. & Peat Moss & Pure & -- & -- \\
6. & Peat Moss & Pure & MMN & + \\
7. & Peat Moss & Pure & PYMDA & ++ \\
8. & Peat Moss & Pure & MMN+PMYDA 1:1 & ++ \\
9. & Vermiculite + Peat Moss & $1: 1$ & - & - \\
10. & Vermiculite + Peat Moss & $1: 1$ & PYMDA & ++ \\
11. & Vermiculite + Peat Moss & $1: 1$ & MMN & + \\
12. & Vermiculite + Peat Moss & $1: 1$ & MMN+PMYDA 1:1 & ++ \\
13. & Vermiculite + Peat Moss & $3 / 4: 1 / 4$ & MMN+PMYDA 1:1 & +++ \\
14. & Vermiculite + Peat Moss & $1 / 4: 3 / 4$ & MMN+PMYDA 1:1 & + \\
15. & Wheat Grains & & -- & ++++ \\
\hline
\end{tabular}

*- Represent no growth of mycelium

** Each + represents $20 \%$ colonization of substrate

uninoculated wasteland soil $(13.16 \mathrm{~cm})$ (Table-2,3,4; Fig iiii). F-ratios for height of seedlings at 3 months $(3.98, \mathrm{df}=$ $5 / 12, \mathrm{P}<0.01), 6$ month $(6.09 \mathrm{df}=5 / 12, \mathrm{P}<0.01)$ and one year (38.36 df $=5 / 12 \mathrm{P}<0.01)$ sampling intervals of samplings were significant. Data analysis by t-test revealed that the seedling height in the inoculated mixture of soils was significantly higher than their respective uninoculated treatments.

Effect of mycorrhizal inoculations on root length: In threemonth-old seedlings, the maximum root length was recorded in seedlings grown in inoculated forest soil $(18.50 \mathrm{~cm})$ and least in uninoculated mixture soil $(14.33 \mathrm{~cm})$. At six-month sampling stage, the maximum root length was recorded in seedlings grown in inoculated mixture of soils $(37.66 \mathrm{~cm})$ and least in uninoculated wasteland soil $(20.00 \mathrm{~cm})$. Similarly, the maximum seedling root length at one-year sampling stage was recorded in inoculated mixture of soils $(32.16 \mathrm{~cm})$ and least in inoculated wasteland soil $(17.00 \mathrm{~cm})$ (Table-2,3,4; Fig. i-iii). The F-ratios for root length at 3, 6, 12 months were recorded $1.10,10.11,10.78(\mathrm{df}=5 / 12)$, respectively. The Fratios for seedling root length at three-month sampling was non-significant suggesting that there were no significant differences between seedling root lengths in different treatments. The data analysis based on t-test revealed that the root length of six-month-old seedlings in inoculated forest soil and inoculated mixture of soils, and one year old seedlings in inoculated forest soil, was significantly higher than their respective uninoculated treatments.

Effect of mycorrhizal inoculations on the number of short roots: Observations on the number of short roots were initiated at an age of 4 months and results are presented for six months and one-year-old seedlings. At the age of six months, the number of short roots was maximum in seedlings raised in an inoculated mixture of soils (490.33), and least in uninoculated wasteland soil (112.00). Similarly, at one-year sampling stage, the maximum number of short roots were recorded in seedlings raised in inoculated mixture of soils

*** Formaldehyde $40 \%=5.00 \mathrm{~mL}$, Ethyl Alcohol $70 \%=90 \mathrm{~mL}$, Acetic Acid $=5.00 \mathrm{~mL}$ 
Table-2: Growth and development of 3 month old containerized seedlings of Cedrus deodara

\begin{tabular}{|c|c|c|c|c|c|c|c|c|c|c|c|}
\hline $\begin{array}{l}\text { S. } \\
\text { No. }\end{array}$ & Treatments & $\begin{array}{l}\text { Height } \\
\text { (cms) }\end{array}$ & $\begin{array}{l}\text { Root } \\
\text { length } \\
(\mathrm{cms})\end{array}$ & $\begin{array}{l}\text { Shoot } \\
\text { fresh } \\
\text { weight } \\
\text { (mgs) }\end{array}$ & $\begin{array}{l}\text { Root } \\
\text { fresh } \\
\text { wEight } \\
\text { (mgs) }\end{array}$ & $\begin{array}{l}\text { Shoot } \\
\text { dry } \\
\text { weight } \\
\text { (mgs) }\end{array}$ & $\begin{array}{l}\text { Root dry } \\
\text { weight } \\
\text { (mgs) }\end{array}$ & $\begin{array}{l}\text { Total } \\
\text { fresh } \\
\text { weight } \\
\text { (mgs) }\end{array}$ & $\begin{array}{l}\text { Total } \\
\text { dry } \\
\text { weight } \\
\text { (mgs) }\end{array}$ & $\begin{array}{l}\text { Root/ } \\
\text { shoot ratio } \\
\text { (fresh } \\
\text { weight } \\
\text { basis) }\end{array}$ & $\begin{array}{l}\text { Root / shoot } \\
\text { ratio } \\
\text { (dry weight } \\
\text { basis) }\end{array}$ \\
\hline 1. & $\begin{array}{l}\text { Wasteland soil } \\
\text { (Uninoculated ) }\end{array}$ & $\begin{array}{l}10.33 \\
(0.57)\end{array}$ & $\begin{array}{l}15.20 \\
(2.09)\end{array}$ & $\begin{array}{l}442.00 \\
(17.80)\end{array}$ & $\begin{array}{l}135.00 \\
(0.00)\end{array}$ & $\begin{array}{l}222.66 \\
(32.75)\end{array}$ & $\begin{array}{l}57.00 \\
(3.00)\end{array}$ & $\begin{array}{l}577.13 \\
(17.80)\end{array}$ & $\begin{array}{l}279.66 \\
(29.75)\end{array}$ & $\begin{array}{l}0.30 \\
(0.01)\end{array}$ & $\begin{array}{l}0.25 \\
(0.05)\end{array}$ \\
\hline 2. & $\begin{array}{l}\text { Forest soil } \\
\text { (Uninoculated ) }\end{array}$ & $\begin{array}{c}9.66 \\
(1.15)\end{array}$ & $\begin{array}{l}15.50 \\
(3.50)\end{array}$ & $\begin{array}{l}474.16 \\
(74.94)\end{array}$ & $\begin{array}{l}117.66 \\
(6.80)\end{array}$ & $\begin{array}{c}209.40 \\
(5.91)\end{array}$ & $\begin{array}{l}42.33 \\
(2.08)\end{array}$ & $\begin{array}{l}591.06 \\
(78.82)\end{array}$ & $\begin{array}{l}251.80 \\
(3.92)\end{array}$ & $\begin{array}{c}0.25 \\
(0.03)\end{array}$ & $\begin{array}{l}0.20 \\
(0.01)\end{array}$ \\
\hline 3. & $\begin{array}{l}\text { Mixture of soils } \\
\text { (Uninoculated ) }\end{array}$ & $\begin{array}{l}14.16 \\
(1.75)\end{array}$ & $\begin{array}{l}14.33 \\
(1.52)\end{array}$ & $\begin{array}{l}526.00 \\
(35.11)\end{array}$ & $\begin{array}{l}201.00 \\
(18.52)\end{array}$ & $\begin{array}{l}325.33 \\
(56.43)\end{array}$ & $\begin{array}{l}95.80 \\
(1.04)\end{array}$ & $\begin{array}{l}761.00 \\
(41.86)\end{array}$ & $\begin{array}{l}421.13 \\
(55.89)\end{array}$ & $\begin{array}{c}0.35 \\
(0.03)\end{array}$ & $\begin{array}{c}0.29 \\
(0.04)\end{array}$ \\
\hline 4. & $\begin{array}{l}\text { Wasteland soil } \\
\text { (Inoculated ) }\end{array}$ & $\begin{array}{l}10.75 \\
(0.75)\end{array}$ & $\begin{array}{l}15.26 \\
(1.06)\end{array}$ & $\begin{array}{l}496.66 \\
(4.16)\end{array}$ & $\begin{array}{l}173.33 \\
(14.30)\end{array}$ & $\begin{array}{l}218.23 \\
(32.68)\end{array}$ & $\begin{array}{l}72.53 \\
(2.50)\end{array}$ & $\begin{array}{l}669.96 \\
(16.66)\end{array}$ & $\begin{array}{l}290.76 \mathrm{c} \\
(33.85)\end{array}$ & $\begin{array}{c}0.34 \\
(0.02)\end{array}$ & $\begin{array}{l}0.33 \\
(0.04)\end{array}$ \\
\hline 5. & $\begin{array}{l}\text { Forest soil } \\
\text { (Inoculated ) }\end{array}$ & $\begin{array}{l}13.83 \\
(5.00)\end{array}$ & $\begin{array}{l}18.50 \\
(3.27)\end{array}$ & $\begin{array}{c}703.33 \\
(310.05)\end{array}$ & $\begin{array}{c}265.00 \\
(125.59)\end{array}$ & $\begin{array}{l}266.66 \\
(70.94)\end{array}$ & $\begin{array}{l}86.56 \\
(3.18)\end{array}$ & $\begin{array}{c}968.33 \\
(434.75)\end{array}$ & $\begin{array}{l}353.253 \\
(72.56)\end{array}$ & $\begin{array}{l}0.37 \\
(0.11)\end{array}$ & $\begin{array}{c}0.33 \\
(0.09)\end{array}$ \\
\hline 6. & $\begin{array}{l}\text { Mixture of soils } \\
\text { (Inoculated) }\end{array}$ & $\begin{array}{l}16.22 \\
(0.75)\end{array}$ & $\begin{array}{l}15.83 \\
(1.60)\end{array}$ & $\begin{array}{l}1250.20 \\
(264.85)\end{array}$ & $\begin{array}{l}448.38 \\
(50.58)\end{array}$ & $\begin{array}{l}530.96 \\
(42.47)\end{array}$ & $\begin{array}{l}193.05 \\
(11.72)\end{array}$ & $\begin{array}{l}1695.58 \\
(307.27)\end{array}$ & $\begin{array}{l}719.65 \\
(45.62)\end{array}$ & $\begin{array}{c}0.36 \\
(0.04)\end{array}$ & $\begin{array}{c}0.36 \\
(0.01)\end{array}$ \\
\hline
\end{tabular}

Figures in parenthesis are standard deviations.

(562.33) and least in uninoculated wasteland soil (119.00) (Table-3, 4). The F-ratios for number of short roots at 6month $(232.58, \mathrm{df}=5 / 12, \mathrm{P}<0.01)$ and one year $(151.69, \mathrm{df}=$ $5 / 12, \mathrm{P}<0.01)$ stages of sampling were significant. The data analysis revealed that the number of short roots in six months and one-year sampling stages was significantly higher in inoculated wasteland soil, inoculated forest soil, and inoculated mixture of soils than that in their respective uninoculated treatments.

Effect of mycorrhizal inoculations on number of mycorrhizal roots: Mycorrhizal short roots were counted in seedlings at $5^{\text {th }}$ month, $6^{\text {th }}$ month, and one-year growth stages. In six-month-old seedlings, the number of mycorrhizal short roots was highest in seedlings raised in inoculated mixture of soils $(448.33,91.43 \%)$ and least in uninoculated wasteland soil $(44.33,39.58 \%)$. Similarly, in one-year-old seedlings, the mycorrhizal short roots in seedlings grown in inoculated mixture of soils were maximum $(552.33,98.22 \%)$ and least in uninoculated wasteland soil $(38.66,32.48 \%)$ (Table-3, 4). The F-ratios for mycorrhizal short root numbers at $6^{\text {th }}$ month (280.96, $\mathrm{df}=5 / 12, \mathrm{P}<0.01)$ and one-year stage $(518.71, \mathrm{df}=$ $5 / 12, \mathrm{P}<0.01)$ were significant. The data analysis revealed that in six month and one-year sampling stages, the number of mycorrhizal short roots in inoculated wasteland soil, inoculated forest soil, and inoculated mixture of soils was significantly higher than their respective uninoculated treatments.

Effect of mycorrhizal inoculations on shoot fresh and dry weight: At three month sampling stage, the fresh and dry weights of shoot was maximum in seedlings raised in inoculated mixture of soils $(1250.20,530.96 \mathrm{mg})$, and least in uninoculated wasteland soil (442.00, $222.66 \mathrm{mg})$. Similarly, in six-month-old seedlings the fresh and dry weight of shoot was maximum in seedlings grown in an inoculated mixture of soils $(4753.93,2129.10 \mathrm{mg})$ and minimum in uninoculated wasteland soil $(890.13,369.60 \mathrm{mg})$. Likewise in one-year-old seedlings, the fresh, dry weight of shoot was highest in seedlings raised in an inoculated mixture of soils (11396.33, $3607.07 \mathrm{mg}$ ) and lowest in uninoculated wasteland soil (1646.43, $700.70 \mathrm{mg}$ ) (Table- 2,3,4). F-ratios for fresh, dry weight of shoot at 3 month $(9.87,22.38, \mathrm{df}=5 / 12, \mathrm{P}<0.01), 6$ month $(219.18,152.20$, df $5 / 12, \mathrm{P}<0.01)$ and one year (403.04, 551.73, $\mathrm{df}=5 / 12, \mathrm{P}<0.01)$ intervals were significant (Table-5). The data analysis revealed that the fresh and dry weight of shoot was significantly higher in inoculated seedlings in comparison to their respective control.

Table 3: Growth and development of 6 month old containerized seedlings of Cedrus deodara

\begin{tabular}{|c|c|c|c|c|c|c|c|c|c|c|c|c|c|c|c|c|}
\hline $\begin{array}{l}\text { S. } \\
\text { No. }\end{array}$ & Treatments & $\begin{array}{l}\text { Height } \\
\text { (cms) }\end{array}$ & $\begin{array}{l}\text { Root } \\
\text { length } \\
\text { (cms) }\end{array}$ & $\begin{array}{l}\text { No. of } \\
\text { short } \\
\text { roots }\end{array}$ & $\begin{array}{l}\text { No. of } \\
\text { mycor } \\
\text { rhizal } \\
\text { short } \\
\text { roots }\end{array}$ & $\begin{array}{l}\text { Perce } \\
\text { ntage } \\
\text { of } \\
\text { mycor } \\
\text { rhizal } \\
\text { short } \\
\text { roots } \\
\end{array}$ & $\begin{array}{l}\text { Shoot } \\
\text { fresh } \\
\text { weight } \\
\text { (mgs) }\end{array}$ & $\begin{array}{l}\text { Root } \\
\text { fresh } \\
\text { weight } \\
\text { (mgs) }\end{array}$ & $\begin{array}{l}\text { Shoot } \\
\text { dry } \\
\text { weight } \\
\text { (mgs) }\end{array}$ & $\begin{array}{l}\text { Root } \\
\text { dry } \\
\text { weight } \\
\text { (mgs) }\end{array}$ & $\begin{array}{l}\begin{array}{c}\text { Total } \\
\text { fresh }\end{array} \\
\text { weight } \\
\text { (mgs) }\end{array}$ & $\begin{array}{l}\text { Total } \\
\text { dry } \\
\text { weight } \\
\text { (mgs) }\end{array}$ & $\begin{array}{l}\text { Root/ } \\
\text { shoot } \\
\text { ratio } \\
\text { (fresh } \\
\text { weight } \\
\text { basis) }\end{array}$ & $\begin{array}{l}\text { Root / } \\
\text { Shoot } \\
\text { ratio } \\
\text { (dry } \\
\text { weight } \\
\text { basis) }\end{array}$ & $\begin{array}{l}\text { Root } \\
\text { collar } \\
\text { dia. } \\
(\mathbf{m m})\end{array}$ & $\begin{array}{l}\text { Seedl } \\
\text { ing } \\
\text { volu } \\
\text { me } \\
\left(\mathrm{cm}^{3}\right)\end{array}$ \\
\hline 1. & $\begin{array}{l}\text { Waste land soil } \\
\text { (Uninoculated ) }\end{array}$ & $\begin{array}{l}12.13 \\
(1.10)\end{array}$ & $\begin{array}{l}20.00 \\
(5.00)\end{array}$ & $\begin{array}{l}112.00 \\
(8.18)\end{array}$ & $\begin{array}{l}44.33 \\
(6.02)\end{array}$ & $\begin{array}{l}39.58 \\
(6.90)\end{array}$ & $\begin{array}{l}890.13 \\
(67.17)\end{array}$ & $\begin{array}{l}407.00 \\
(9.05)\end{array}$ & $\begin{array}{l}369.60 \\
(22.89)\end{array}$ & $\begin{array}{l}182.00 \\
(11.34)\end{array}$ & $\begin{array}{l}1297.13 \\
(75.15)\end{array}$ & $\begin{array}{l}551.60 \\
(25.53)\end{array}$ & $\begin{array}{c}0.45 \\
(0.02)\end{array}$ & $\begin{array}{c}0.49 \\
(0.04)\end{array}$ & $\begin{array}{c}3.33 \\
(0.57)\end{array}$ & $\begin{array}{c}1.34 \\
(0.62)\end{array}$ \\
\hline 2. & $\begin{array}{l}\text { Forest soil } \\
\text { (Uninoculated ) }\end{array}$ & $\begin{array}{l}19.66 \\
(4.04)\end{array}$ & $\begin{array}{l}21.00 \\
(3.00)\end{array}$ & $\begin{array}{l}167.33 \\
(13.57)\end{array}$ & $\begin{array}{l}85.33 \\
(5.03)\end{array}$ & $\begin{array}{l}50.99 \\
(1.14)\end{array}$ & $\begin{array}{c}2039.53 \\
(81.06)\end{array}$ & $\begin{array}{l}622.43 \\
(9.72)\end{array}$ & $\begin{array}{l}965.53 \\
(14.03)\end{array}$ & $\begin{array}{l}272.30 \\
(10.40)\end{array}$ & $\begin{array}{l}2661.96 \\
(90.17)\end{array}$ & $\begin{array}{l}1237.83 \\
(24.06)\end{array}$ & $\begin{array}{c}0.30 \\
(0.01)\end{array}$ & $\begin{array}{c}0.28 \\
(0.00)\end{array}$ & $\begin{array}{c}5.00 \\
(1.00)\end{array}$ & $\begin{array}{c}4.91 \\
(0.96)\end{array}$ \\
\hline 3. & $\begin{array}{l}\text { Mixture of soils } \\
\text { (Uninoculated ) }\end{array}$ & $\begin{array}{l}19.66 \\
(4.04)\end{array}$ & $\begin{array}{l}24.90 \\
(1.57)\end{array}$ & $\begin{array}{l}173.37 \\
(16.25)\end{array}$ & $\begin{array}{c}94.33 \\
(17.78)\end{array}$ & $\begin{array}{l}54.40 \\
(5.40)\end{array}$ & $\begin{array}{l}2718.76 \\
(200.80)\end{array}$ & $\begin{array}{l}831.16 \\
(9.58)\end{array}$ & $\begin{array}{l}1098.46 \\
(199.13)\end{array}$ & $\begin{array}{r}254.83 \\
(7.68)\end{array}$ & $\begin{array}{l}3549.92 \\
(209.29)\end{array}$ & $\begin{array}{l}1353.79 \\
(198.37)\end{array}$ & $\begin{array}{c}0.30 \\
(0.02)\end{array}$ & $\begin{array}{c}0.23 \\
(0.40)\end{array}$ & $\begin{array}{c}6.00 \\
(1.00)\end{array}$ & $\begin{array}{c}7.09 \\
(0.92)\end{array}$ \\
\hline 4. & $\begin{array}{l}\text { Wasteland soil } \\
\text { (Inoculated) }\end{array}$ & $\begin{array}{l}16.00 \\
(1.52)\end{array}$ & $\begin{array}{l}27.00 \\
(2.64)\end{array}$ & $\begin{array}{l}280.66 \\
(10.69)\end{array}$ & $\begin{array}{l}138.00 \\
(28.93)\end{array}$ & $\begin{array}{l}49.16 \\
(8.97)\end{array}$ & $\begin{array}{c}2750.16 \\
(62.94)\end{array}$ & $\begin{array}{l}736.95 \\
(4.80)\end{array}$ & $\begin{array}{l}445.16 \\
(15.00)\end{array}$ & $\begin{array}{l}259.96 \\
(51.24)\end{array}$ & $\begin{array}{l}3487.11 \\
(67.03)\end{array}$ & $\begin{array}{l}705.12 \\
(55.84)\end{array}$ & $\begin{array}{c}0.26 \\
(0.00)\end{array}$ & $\begin{array}{c}0.58 \\
(0.11)\end{array}$ & $\begin{array}{c}3.66 \\
(1.15)\end{array}$ & $\begin{array}{c}2.14 \\
(1.60)\end{array}$ \\
\hline 5. & $\begin{array}{l}\text { Forest soil } \\
\text { (Inoculated ) }\end{array}$ & $\begin{array}{l}20.13 \\
(1.20)\end{array}$ & $\begin{array}{l}28.50 \\
(1.45)\end{array}$ & $\begin{array}{l}420.00 \\
(27.83)\end{array}$ & $\begin{array}{l}363.00 \\
(20.66)\end{array}$ & $\begin{array}{l}86.42 \\
(0.94)\end{array}$ & $\begin{array}{l}4269.60 \\
(329.80)\end{array}$ & $\begin{array}{c}1428.60 \\
(98.67)\end{array}$ & $\begin{array}{l}1908.20 \\
(80.05)\end{array}$ & $\begin{array}{r}485.40 \\
(9.61)\end{array}$ & $\begin{array}{l}5698.20 \\
(423.72)\end{array}$ & $\begin{array}{c}2393.60 \\
(88.41)\end{array}$ & $\begin{array}{c}0.33 \\
(0.01)\end{array}$ & $\begin{array}{c}0.25 \\
(0.00)\end{array}$ & $\begin{array}{c}6.00 \\
(1.73)\end{array}$ & $\begin{array}{c}7.24 \\
(4.48)\end{array}$ \\
\hline 6. & $\begin{array}{l}\text { Mixture of soils } \\
\text { (Inoculated ) }\end{array}$ & $\begin{array}{l}29.16 \\
(1.20)\end{array}$ & $\begin{array}{l}37.66 \\
(5.20) \\
\end{array}$ & $\begin{array}{l}490.33 \\
(10.01) \\
\end{array}$ & $\begin{array}{l}448.33 \\
(12.58) \\
\end{array}$ & $\begin{array}{l}91.43 \\
(3.83) \\
\end{array}$ & $\begin{array}{l}4753.93 \\
(45.42) \\
\end{array}$ & $\begin{array}{r}1460.83 \\
(25.53) \\
\end{array}$ & $\begin{array}{l}2129.10 \\
(127.60)\end{array}$ & $\begin{array}{l}491.80 \\
(13.16) \\
\end{array}$ & $\begin{array}{l}6214.76 \\
(69.48) \\
\end{array}$ & $\begin{array}{l}2620.90 \\
(122.97) \\
\end{array}$ & $\begin{array}{c}0.30 \\
(0.02) \\
\end{array}$ & $\begin{array}{c}0.23 \\
(0.02)\end{array}$ & $\begin{array}{c}7.66 \\
(0.57) \\
\end{array}$ & $\begin{array}{l}17.10 \\
(1.98) \\
\end{array}$ \\
\hline
\end{tabular}

Figures in parenthesis are standard deviations. 
Table 4: Growth and development of one year old containerized seedlings of Cedrus deodara

\begin{tabular}{|c|c|c|c|c|c|c|c|c|c|c|c|c|c|c|c|c|}
\hline $\begin{array}{l}\text { S. } \\
\text { No. }\end{array}$ & Treatments & $\begin{array}{l}\text { Height } \\
\text { (cms) }\end{array}$ & $\begin{array}{l}\text { Root } \\
\text { length } \\
(\mathrm{cms})\end{array}$ & $\begin{array}{l}\text { No. of } \\
\text { short } \\
\text { roots }\end{array}$ & $\begin{array}{l}\text { No. of } \\
\text { mycor } \\
\text { rhizal } \\
\text { short } \\
\text { roots }\end{array}$ & $\begin{array}{l}\text { \%Myc } \\
\text { orrhiza } \\
\text { I short } \\
\text { roots }\end{array}$ & $\begin{array}{l}\text { Shoot } \\
\text { fresh } \\
\text { weight } \\
\text { (mgs) }\end{array}$ & $\begin{array}{l}\text { Root } \\
\text { fresh } \\
\text { weight } \\
\text { (mgs) }\end{array}$ & $\begin{array}{l}\text { Shoot } \\
\text { dry } \\
\text { weight } \\
\text { (mgs) }\end{array}$ & $\begin{array}{l}\text { Root } \\
\text { dry } \\
\text { weight } \\
\text { (mgs) }\end{array}$ & $\begin{array}{l}\text { Total } \\
\text { fresh } \\
\text { weight } \\
(\mathrm{mgs})\end{array}$ & $\begin{array}{l}\text { Total } \\
\text { dry } \\
\text { weight } \\
\text { (mgs) }\end{array}$ & $\begin{array}{l}\text { Root/ } \\
\text { shoot } \\
\text { ratio } \\
\text { (FW } \\
\text { basis) }\end{array}$ & $\begin{array}{l}\text { Root / } \\
\text { shoot } \\
\text { ratio } \\
\text { (DW } \\
\text { basis) }\end{array}$ & $\begin{array}{l}\text { Root } \\
\text { collar } \\
\text { dia } \\
(\mathbf{m m})\end{array}$ & $\begin{array}{l}\text { Seedling } \\
\text { volume } \\
\left(\mathrm{cm}^{3}\right)\end{array}$ \\
\hline 1. & $\begin{array}{l}\text { Wasteland soil } \\
\text { (Uninoculated ) }\end{array}$ & $\begin{array}{l}13.16 \\
(1.25)\end{array}$ & $\begin{array}{l}20.00 \\
(4.00)\end{array}$ & $\begin{array}{l}119.00 \\
(17.69)\end{array}$ & $\begin{array}{l}38.66 \\
(3.51)\end{array}$ & $\begin{array}{l}32.48 \\
(2.69)\end{array}$ & & & & & & & $\begin{array}{l}0.66 \\
(0.07)\end{array}$ & $\begin{array}{l}0.55 \\
(0.03)\end{array}$ & & $(1.25)$ \\
\hline 2. & $\begin{array}{l}\text { Forest soil } \\
\text { (Uninoculated) }\end{array}$ & $\begin{array}{l}19.83 \\
(0.76)\end{array}$ & $\begin{array}{l}20.83 \\
(1.04)\end{array}$ & $\begin{array}{l}201.66 \\
(10.40)\end{array}$ & $\begin{array}{l}88.33 \\
(2.08)\end{array}$ & $\begin{array}{l}43.80 \\
(3.00)\end{array}$ & $\begin{array}{l}4860.56 \\
(148.93)\end{array}$ & $\begin{array}{l}2132.20 \\
(105.94)\end{array}$ & $\begin{array}{l}1387.56 \\
(967.69)\end{array}$ & $\begin{array}{l}932.92 \\
(38.14)\end{array}$ & $\begin{array}{l}6992.76 \\
(254.34)\end{array}$ & & $\begin{array}{l}0.43 \\
(0.01)\end{array}$ & $\begin{array}{l}0.67 \\
(0.01)\end{array}$ & $\begin{array}{l}10.16 \\
(0.04)\end{array}$ & $\begin{array}{l}20.14 \\
(0.74)\end{array}$ \\
\hline 3. & $\begin{array}{l}\text { Mixture of soils } \\
\text { (Uninoculated ) }\end{array}$ & $\begin{array}{l}21.00 \\
(1.32)\end{array}$ & $\begin{array}{l}24.75 \\
(2.64)\end{array}$ & $\begin{array}{l}304.66 \\
(24.50)\end{array}$ & $\begin{array}{l}194.00 \\
(12.28)\end{array}$ & $\begin{array}{l}63.67 \\
(1.83)\end{array}$ & $\begin{array}{l}4062.12 \\
(131.84)\end{array}$ & $\begin{array}{l}2132.13 \\
(34.61)\end{array}$ & $\begin{array}{l}1639.10 \\
(90.19)\end{array}$ & $\begin{array}{l}763.20 \\
(60.40)\end{array}$ & $\begin{array}{l}6194.25 \\
(166.56)\end{array}$ & $\begin{array}{l}2402.30 \\
(150.51)\end{array}$ & $\begin{array}{l}0.52 \\
(0.01)\end{array}$ & $\begin{array}{l}0.46 \\
(0.01)\end{array}$ & $\begin{array}{l}10.14 \\
(0.02)\end{array}$ & $\begin{array}{l}21.29 \\
(1.27)\end{array}$ \\
\hline 4. & $\begin{array}{l}\text { Waste land soil } \\
\text { (Inoculated ) }\end{array}$ & $\begin{array}{l}17.00 \\
(2.64)\end{array}$ & $\begin{array}{l}17.00 \\
(2.64)\end{array}$ & $\begin{array}{l}292.33 \\
(15.53)\end{array}$ & $\begin{array}{l}144.66 \\
(17.61)\end{array}$ & $\begin{array}{l}49.48 \\
(3.48)\end{array}$ & $\begin{array}{l}3263.43 \\
(62.23)\end{array}$ & $\begin{array}{l}1761.43 \\
(136.54)\end{array}$ & $\begin{array}{l}1420.63 \\
(44.78)\end{array}$ & $\begin{array}{l}667.73 \\
(24.03)\end{array}$ & $\begin{array}{l}5024.86 \\
(184.22)\end{array}$ & $\begin{array}{l}2088.36 \\
(41.42)\end{array}$ & $\begin{array}{l}0.53 \\
(0.05)\end{array}$ & $\begin{array}{l}0.47 \\
(0.02)\end{array}$ & $\begin{array}{l}10.07 \\
(0.06)\end{array}$ & $\begin{array}{l}17.11 \\
2.53)\end{array}$ \\
\hline 5. & $\begin{array}{l}\text { Forest soil } \\
\text { (Inoculated ) }\end{array}$ & $\begin{array}{l}21.16 \\
(1.60)\end{array}$ & $\begin{array}{l}27.73 \\
(1.52)\end{array}$ & $\begin{array}{l}446.33 \\
(18.03)\end{array}$ & $\begin{array}{l}316.33 \\
(18.03)\end{array}$ & $\begin{array}{l}70.87 \\
(1.17)\end{array}$ & $\begin{array}{l}8833.73 \\
(87.91)\end{array}$ & $\begin{array}{l}3832.70 \\
(66.72)\end{array}$ & $\begin{array}{l}3024.00 \\
(94.84)\end{array}$ & $\begin{array}{l}1403.86 \\
(12.53)\end{array}$ & $\begin{array}{l}12666.43 \\
(132.23)\end{array}$ & $\begin{array}{l}4427.86 \\
(105.75)\end{array}$ & $\begin{array}{l}0.43 \\
(0.00)\end{array}$ & $\begin{array}{l}0.46 \\
(0.01)\end{array}$ & $\begin{array}{l}10.20 \\
(0.01)\end{array}$ & $\begin{array}{l}21.58 \\
(1.63)\end{array}$ \\
\hline 6. & $\begin{array}{l}\text { Mixture of soils } \\
\text { (Inoculated ) }\end{array}$ & $\begin{array}{l}30.46 \\
(1.45)\end{array}$ & $\begin{array}{l}32.16 \\
(4.19)\end{array}$ & $\begin{array}{l}562.33 \\
(21.59)\end{array}$ & $\begin{array}{l}552.33 \\
(37.23)\end{array}$ & $\begin{array}{l}98.22 \\
(0.48)\end{array}$ & $\begin{array}{l}11396.33 \\
(730.29)\end{array}$ & $\begin{array}{l}4096.36 \\
(62.22)\end{array}$ & $\begin{array}{l}3607.07 \\
(107.12)\end{array}$ & $\begin{array}{l}1365.68 \\
(59.65)\end{array}$ & $\begin{array}{l}15492.69 \\
(729.44)\end{array}$ & $\begin{array}{l}4972.95 \\
(165.24)\end{array}$ & $\begin{array}{l}0.35 \\
(0.01)\end{array}$ & $\begin{array}{l}0.37 \\
(0.00)\end{array}$ & $\begin{array}{l}10.23 \\
(0.02)\end{array}$ & $\begin{array}{l}31.16 \\
(1.64)\end{array}$ \\
\hline
\end{tabular}

Effect of mycorrhizal inoculations on root fresh and dry weight: At three-month sampling stage, the highest fresh, dry weight of roots was recorded for the seedlings grown in inoculated mixture of soils $(448.38,193.05 \mathrm{mg})$ and lowest in uninoculated forest soil $(117.66,42.30 \mathrm{mg})$. While at sixmonth old samplings, the fresh, dry weight of roots of seedlings was maximum in the inoculated mixture of soils $(1460.83,491.80 \mathrm{mg})$ and minimum in uninoculated wasteland soil $(407.00,182.00 \mathrm{mg})$. In one year, sampling, the fresh, dry weight was highest in the inoculated mixture of soils $(4096.36,1365.68 \mathrm{mg}$ ) and minimum in uninoculated wasteland soil (1088.26, $391.93 \mathrm{mg}$ ) (Table-2,3,4). F-ratios fresh, dry weight of roots at three month $(14.13,306.46 \mathrm{df}=$ $5 / 17, \mathrm{P}<0.01), 6$ month $(318.26,97.03, \mathrm{df}=5 / 12, \mathrm{P}<0.01)$ and one year $(454.30,229.39, \mathrm{df}=5 / 12, \mathrm{P}<0.01)$ were significant (Table-5). The data analysis revealed that fresh and dry weight of roots was significantly higher in the seedlings inoculated with mycorrhizal fungi as compared to respective uninoculated treatments.

Effect of mycorrhizal inoculations on total fresh and dry weight of seedling: At three-month sampling, the total fresh, dry weight of seedlings was highest in inoculated mixture of soils $(1695.58,719.65 \mathrm{mg})$ and lowest in uninoculated wasteland soil $(577.13,279.66 \mathrm{mg})$. Similarly, total fresh and dry weight of six-month-old seedlings was maximum in the inoculated mixture of soils $(6214.93,2620.90 \mathrm{mg})$ and minimum in uninoculated wasteland soil $(1297.13,551.60 \mathrm{mg})$. At one-year sampling, the total fresh, dry weight of seedlings was highest in inoculated mixture of soils $(15492.69,4972.95 \mathrm{mg})$ and minimum in uninoculated wasteland soil $(2734.70,1092.60$ $\mathrm{mg}$ ) (Table-2,3,4). F-ratios for total fresh and dry weight of the seedlings at 3 month $(11.17,43.71, \mathrm{df}=5 / 12, \mathrm{P}<0.01), 6$ month $(250.56,198.41, \mathrm{df}=5 / 12, \mathrm{P}<0.01)$ and one year $(60.32,447.72, \mathrm{df}=5 / 12, \mathrm{P}<0.01)$ stages and were found to be significant (Table-5). Data analysis revealed that total fresh and dry weight of seedlings at three-month sampling stage in inoculated wasteland soil and an inoculated mixture of soils, six month and one-year sampling stages in inoculated wasteland soil, inoculated forest soil, and inoculated mixture of soils was significantly higher than that in their respective uninoculated treatments.

Effect of mycorrhizal inoculations on the root to shoot ratio: The root/ shoot ratio was determined based on fresh and dry weight. The observations revealed that at three-month sampling, the root/shoot ratio on the fresh weight basis was lowest in uninoculated forest soil $(0.25)$ and highest in inoculated forest soil $(0.37)$. The root/shoot ratio on the dry weight basis was minimum in uninoculated forest soil $(0.20)$ and maximum in mixture of inoculated soils (0.36). At six month sampling, the root/shoot ratio on fresh weight basis was lowest in inoculated wasteland soil $(0.26)$ and maximum in uninoculated wasteland soil $(0.45)$, while on dry weight basis it was lowest in uninoculated and inoculated mixture of soils (0.23) and highest in inoculated wasteland soil (0.58). Root/shoot ratio on fresh weight at one-year sampling was lowest in inoculated mixture of soils (0.35) and highest in uninoculated wasteland soil (0.66). Similarly, on dry weight basis it was lowest in inoculated mixture of soils $(0.37)$ and highest in uninoculated forest soil $(0.67)($ Table-2,3,4).

Table 5: F-Value (ANOVA) for different parameters on growth and development of inoculated and uninoculated seedlings

\begin{tabular}{|c|c|c|c|c|c|c|c|c|c|c|c|c|c|c|c|c|}
\hline $\begin{array}{l}\text { S. } \\
\text { No. }\end{array}$ & $\begin{array}{l}\text { Sampling } \\
\text { stages }\end{array}$ & Height & $\begin{array}{l}\text { Root } \\
\text { length }\end{array}$ & $\begin{array}{l}\text { No. of } \\
\text { short } \\
\text { roots }\end{array}$ & $\begin{array}{l}\text { Mycorrhiz } \\
\text { al short } \\
\text { roots }\end{array}$ & $\begin{array}{l}\text { Percentage } \\
\text { of } \\
\text { mycorrhiz } \\
\text { al short } \\
\text { roots }\end{array}$ & $\begin{array}{l}\text { fresh } \\
\text { weight } \\
\text { shoot }\end{array}$ & $\begin{array}{l}\text { Fresh } \\
\text { weight } \\
\text { root }\end{array}$ & $\begin{array}{l}\text { Dry } \\
\text { weight } \\
\text { shoot }\end{array}$ & $\begin{array}{l}\text { Dry } \\
\text { weight } \\
\text { root }\end{array}$ & $\begin{array}{l}\text { Total } \\
\text { fresh } \\
\text { weight }\end{array}$ & $\begin{array}{l}\text { Total dry } \\
\text { weight }\end{array}$ & $\begin{array}{l}\text { Root/ } \\
\text { shoot } \\
\text { ratio } \\
\text { (fresh } \\
\text { weight } \\
\text { basis) }\end{array}$ & $\begin{array}{l}\text { Root / } \\
\text { shoot } \\
\text { ratio } \\
\text { (dry } \\
\text { weight } \\
\text { basis) }\end{array}$ & $\begin{array}{l}\text { Root } \\
\text { collar } \\
\text { dia. } \\
(\mathrm{mm})\end{array}$ & $\begin{array}{l}\text { Seedling } \\
\text { volume } \\
\left(\mathrm{cm}^{3}\right)\end{array}$ \\
\hline 1. & $2^{1} / 2$ months & $05 * *$ & $2.81 *$ & & & & $9.15^{* *}$ & $10.10^{* *}$ & $4.15^{* *}$ & 2.76 & $12.74 * *$ & $3.11 * *$ & $7.36^{* *}$ & $6.11 * *$ & & \\
\hline 2. & 3 months & $3.98 * *$ & 1.10 & & & & $9.87 * *$ & $14.13^{* *}$ & $22.38^{* *}$ & $306.46 * *$ & $11.17 * *$ & $43.71 * *$ & $7.10^{* *}$ & $3.82 * *$ & & \\
\hline 3. & 4 months & $93.02 * *$ & $62.46^{* *}$ & $30.23^{* *}$ & & & $18.31^{* *}$ & $27.24^{* *}$ & $115.92 * *$ & $18.85^{* * *}$ & $21.79 * *$ & $93.34 * *$ & $1.58^{* *}$ & $6.55^{* *}$ & $4.60 * *$ & $6.24 * *$ \\
\hline 4. & 5 months & $5.06^{*}$ & $25.43^{* *}$ & $208.52 * *$ & $365.73 * *$ & $21.03^{* *}$ & $87.27^{* *}$ & $129.34 * *$ & $116.09^{* *}$ & $225.32 * *$ & $161.74 * *$ & $132.86^{* *}$ & $58.84^{* *}$ & $52.82 * *$ & $4.52 * *$ & $10.42 * *$ \\
\hline 5. & 6 months & $6.09 * *$ & $10.11^{* *}$ & $232.58 * *$ & $280.96 * *$ & $48.105^{* *}$ & $219.80 * *$ & $318.26^{* *}$ & $152.20 * *$ & $97.03 * *$ & $250.56^{* *}$ & $198.42 * *$ & $57.56^{* *}$ & $24.93 * *$ & $6.79^{* *}$ & $20.04 * *$ \\
\hline 6. & One year & $38.36 *$ & $10.78^{* *}$ & $151.69^{* *}$ & $518.71^{* *}$ & $302.04 * *$ & $403.42 * *$ & $454.30^{* *}$ & $551.73^{* *}$ & $229.39^{* *}$ & $60.32 * *$ & $447.72 * *$ & $24.57^{* *}$ & 85.17 & $7.70^{* *}$ & $45.34 * *$ \\
\hline
\end{tabular}



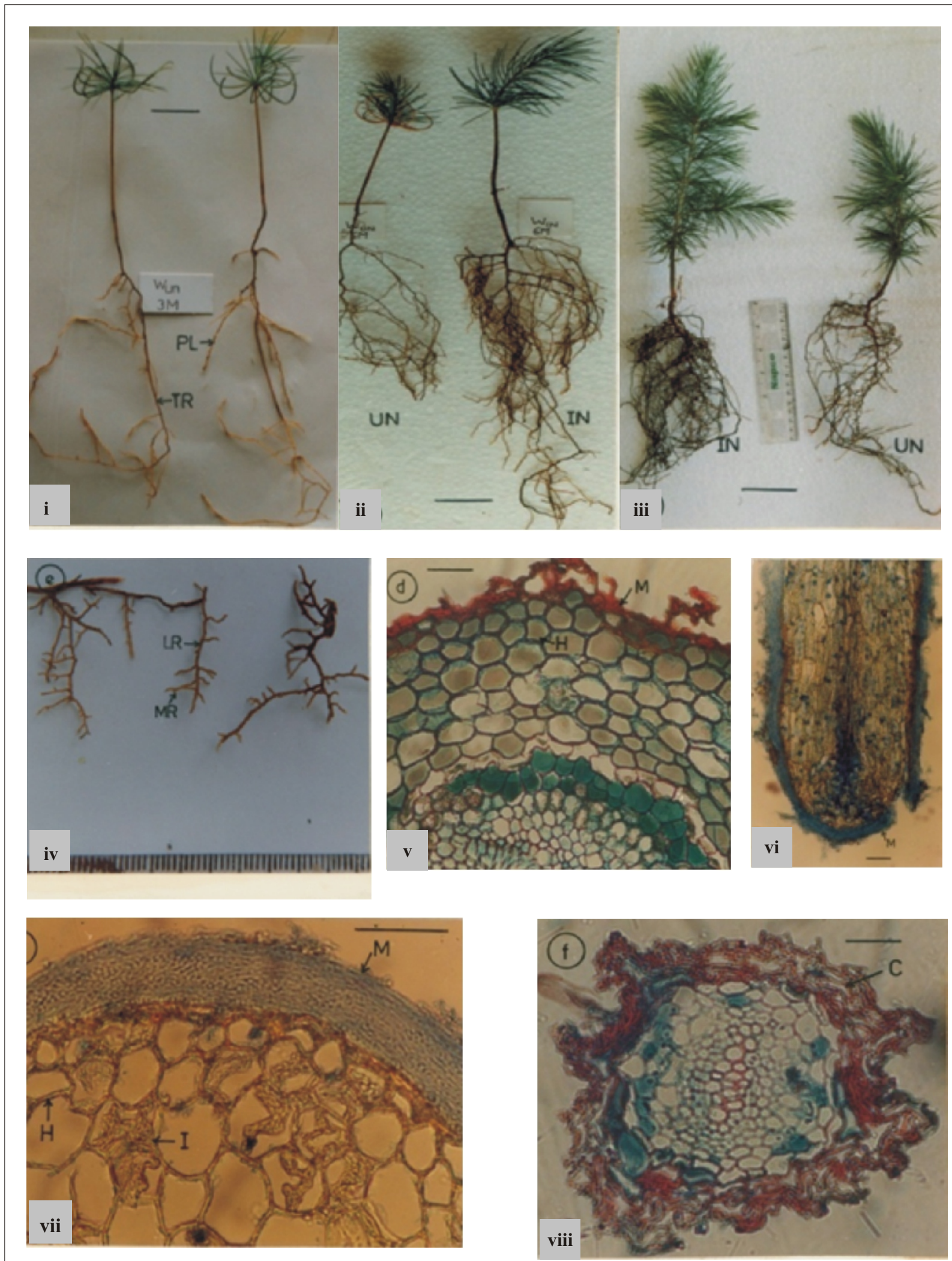

Figs. (i-viii) i. Three months old uninoculated (UN) seedlings, ii. Six-month-old UN and inoculated (IN) seedlings, iii. One year old UN and IN seedlings, iv. Mycorrhizal short and long roots, v. Hartig net (H), and mantle (M) on long roots, vi. L.S. of mycorrhizal short root from uninoculated wasteland soil showing mantle on root tip, vii. T.S. of mycorrhizal short root, viii. T.S. of mycorrhizal short root showing degenerating cortex (C) 
Effect of mycorrhizal inoculations on collar diameter: Collar diameter was recorded at 4, 5, 6 month, and one-year sampling stages. In six-month-old seedlings it was highest in inoculated mixture of soils $(7.66 \mathrm{~mm})$ and lowest in uninoculated wasteland soil $(3.33 \mathrm{~mm})$. Likewise, in oneyear-old seedlings, the root collar diameter was highest in inoculated mixture of soils $(10.23 \mathrm{~mm})$ and lowest in uninoculated wasteland soil $(10.06 \mathrm{~mm})($ Table-3,4). F-ratios for collar diameter at 6 month $(6.79, \mathrm{df}=5 / 12, \mathrm{P}<0.01)$ and one year $(7.70, \mathrm{df}=5 / 12, \mathrm{P}<0.01)$ were significant. Data analysis revealed that collar diameter was significantly higher in inoculated soil as compared to uninoculated soil (Table-5).

Effect of mycorrhizal inoculations on seedling volume: Seedling volume at six-month and one-year old seedlings was highest in inoculated mixture of soils $\left(17.10,31.16 \mathrm{~cm}^{3}\right)$ and lowest in uninoculated wasteland soil $\left(1.34,13.31 \mathrm{~cm}^{3}\right)$ (Table-3,4). F-ratios for seedling volume at 6 month (20.04, $\mathrm{df}=5 / 12, \mathrm{P}<0.01)$ and one year $(45.34, \mathrm{df}=5 / 12, \mathrm{P}<0.01)$ were significant. Data analysis revealed a significantly higher volume of inoculated seedlings in comparison to control (Table-5).

\section{Mycorrhizal development in the seedlings of Cedrus deodara}

Mycorrhizal colonization in long roots: In 15 days old seedlings, only tap root was visible and primary laterals started appearing in 30-day old seedlings. In 45 day, old seedlings, the secondary laterals had already formed on primary laterals and were seen further branching in 60-day old seedlings. Till this stage, seedlings grown in all the three types of soils were similar in root morphology. Anatomically it was observed that the fungus colonized the surface of long laterals before cortex infection in 1-1 1/2-month-old seedlings. The long laterals, in 2-4-month-old seedlings showed a typical Hartig net (Fig. v). The apices of long laterals were pointed and creamish white to light yellow and without any fungal infection. Anatomically the long laterals were similar in inoculated and uninoculated treatments.

Mycorrhizal colonization of short roots in uninoculated treatments: Mycorrhizal colonisation in short roots of seedlings started almost at the age of $2 \frac{1}{2}$ months and differences in the extent of mycorrhization also became apparent at this time in the three types of soils. In uninoculated wasteland soil, the mycorrhizal roots in 21/2 - 4-month-old seedlings were either monopodial or branched but not coralloid. The short roots were 3-6 cm in length, light coloured as compared to similar roots in other treatments. However, with age, the roots became uniformly dark brown. In morphology, they were like the uninfected roots except for the absence of root hairs. Anatomically, in non-mycorrhizal roots of $2 \frac{1}{2}$ month seedlings, the cortex of parenchymatous cells with large intercellular spaces was visible. While in roots of seedlings of the same age, the whole cortex was seen to be completely colonized by the mycorrhizal fungus. In 4-5month-old seedlings, the fungus was seen to penetrate intracellular spaces and form a well-defined white 20-30 $\mu \mathrm{m}$ thick mantle, composed of coarse hyphae. In six-month-old seedlings the mantle sheath became $30-40 \mu \mathrm{m}$ thick without any colour change and still composed of coarse hyphae (Fig. vii). At this stage, the fungal mantle covered the root tip completely and the root appeared to be blunt consequently (Fig. vi). The morphoanatomical characters suggest it to be ectendornycorrhiza.

In uninoculated forest soil and mixture of soils, the mycorrhiza was of ectendomyocrrhizal type. In the seedlings raised in these two types of soils, the short roots were not uniformly coloured as observed in uninoculated wasteland soil. The root was white at the tip and brownish elsewhere. In 4-5-month-old seedlings, the entire root became uniformly dark brown. In the transverse section of $2 \frac{1}{2}$-month-old seedling roots, the cortex became colonized with fungal hyphae. There is intense intercellular penetration and less intracellular penetration by these hyphae. In a longitudinal section, the intracellular hyphae run longitudinally and bear clamp connections. In 5-6-month-old seedling roots, a thin and irregular mantle was observed. Whereas mantle was prominent in uninoculated wasteland soil at this stage.

Mycorrhizal colonization of short roots in inoculated treatments: Mycorrhization of short roots started after the seedlings were $2 \frac{1}{2}$ month old in the three different soils inoculated artificially with wheat grain spawn. Morphologically mycorrhizal short roots were monopodial or branched racemosely (Fig. iv). The mycorrhizal short roots were 3-6 cm in length. The short roots were white at the tip and yellowish brown elsewhere. However, in 4-5-month-old seedlings, the roots acquired uniformly dark brown coloration. In morphology, the short roots were similar in all the three inoculated soils except that these were slightly thicker in inoculated wasteland soil. The anatomical details of infected and uninfected roots observed in all the inoculated soils revealed that in 2-month-old seedlings uninfected roots possessed a cortex of parenchymatous cells with larger intercellular spaces. In mycorrhizal short roots of the same age, the whole cortex was colonized with mycorrhizal fungus. In 3-4-month-old seedlings, fungal infection was further intensified between cortical cells. No intracellular infection of the cortex was observed except a few hyphae in roots of inoculated seedlings grown in forest soil. In mycorrhizal roots of 4-5 months, old seedlings were observed a thin fungal sheath of about $10-15 \mu \mathrm{m}$ thickness. In six-month-old seedlings, some of the mycorrhizal roots were observed at the senescent stage. They became dark brown in colour and cortex cells collapsed (Fig. viii). The stelar region was free of infection. Mycorrhiza in all the inoculated treatments was ectomycorrhiza which resembles the one collected from the field along with fruit bodies of Rhizopogon himalayensis.

\section{DISCUSSION}

In vitro synthesis of ectomycorrhiza between Cedrus deodara and Rhizopogon himalayensis was reported recently (Singh et $a l ., 2020)$. They reported best colonisation of $R$. himalayensis on wheat grains, followed by vermiculite peat moss mixture. Similar observations with other mycobionts have been reported by others. Park (1971) and Gobi (1975) recorded best growth of ectomycorrhizal fungi on wheat grains. Marx and Bryan (1970, 1975) and Marx (1980) observed vermiculite peat moss mixture moistened with a modification 
of Melin-Norkrans medium with glucose instead of sucrose to be an excellent substrate for the production of mycelial culture of Pisolithus tinctorius, Thelephora terrestris and Cenococcum graniforme. Pure culture of Rhizopogon himalayensis also colonized the best on vermiculite saturated with Pridham Yeast Malt Dextrose solution but only when raised in small test tubes and not in bulk perhaps due to poor aeration.

In the present study, the inoculated seedlings of $C$. deodara in three different soils were evaluated for performance under glasshouse conditions. Initially, there were no significant differences in growth of inoculated and uninoculated seedlings of $C$. deodara. After two and a half months, the inoculated seedlings showed a significant increase over uninoculated ones and the height and root length were more in inoculated seedlings than the uninoculated ones. These observations are in conformity with some such other investigations (Asif et al., 2013; Kaewgrajang et al., 2019).

Since the uninoculated soils were not sterilized there is a likelihood of natural inoculum in them. So, a comparison was also made among the three uninoculated soils for statistical significance in seedling height as to which one of these soils supports a better height of seedlings without inoculation. The results support those obtained with the inoculated soils. It is clear, therefore, that the wasteland soil if to be rehabilitated will have to be mixed with soil either having natural inoculum or supplemented with artificial inoculum. Further, it also becomes clear that the seedlings raised in a mixture of soils perform better than those raised in forest soil or wasteland soil. This seems to be because mixture of soils has better moisture-holding capacity and is well aerated than the other two soil types. A mixture of soils and forest soil contains sufficient natural inoculum of mycorrhizal fungi to initiate mycorrhizal infection and consequently show increased growth and development of seedlings.

It is clear from the study that artificial inoculation of $C$. deodara seedlings with $R$. himalayensis can produce seedlings of $C$. deodara of $25-30 \mathrm{~cm}$ height within 6 months. In the nursery practices being presently followed, the same height is attained with natural inoculum almost in $1 \frac{1}{2}-2$ years. Therefore, artificial inoculation with a specific mycorrhizal fungus is doubtlessly beneficial. Further, it is also clear from the results obtained with different soils that wasteland soil if used in mixture with $50 \%$ natural zone soil, produces better results as far as the seedling growth is concerned. In fact, a mixture of soil, whether inoculated or uninoculated gives a better result than the other types of soil. Hence, in nursery practices when a pure culture of fungus is not available for inoculating the seedlings, a mixture of soils should be preferred over other types of soils, even when natural inoculum is used.

The number of short roots and mycorrhizal short roots was more in inoculated seedlings than in uninoculated seedlings. Statistical comparisons between the three inoculated soils revealed that the number of short roots and mycorrhizal short roots was significantly higher in a mixture of soils than wasteland soil at almost all the sampling stages.
Marx et al. (1970) in loblolly pine seedlings, Graham and Linderman (1980) in douglas fir seedlings and Yang and Wilcox (1984) in Pinus resinosa seedlings reported an increase in short roots of the inoculated seedlings. Slankis (1973) explained the increase in the number of short roots in the inoculated seedlings on the basis that mycorrhizal fungi produce hormones and growth factors that alter root physiology and morphology of roots.

The mean values for fresh and dry weight of shoot, root, and seedlings in all inoculated seedlings/soils were significantly higher than that in uninoculated seedlings/soils. Among the three inoculated soil types, fresh and dry weight of shoot, root, and seedlings were more in the mixture of soil, followed by that in forest soil and wasteland soil. Marx et al. (1976, 1977); Hung et al. (1982); Hung and Molina (1986); Ruehle et al. (1981a); Asif et al. (2013); Holusa et al. (2015) also reported a significant increase in the fresh weight of root and shoot of different pines inoculated with $P$. tinctorius. There are reports contrary to this observation also (Ruehle, 1980; Riffle and Tinus, 1982).

Root/shoot ratio in inoculated soils/ seedlings was anticipated to be less than the uninoculated seedlings. The results indicate that during early samplings, i.e. at $2 \frac{1}{2}$ and 3 months the root/shoot ratio (on a fresh and dry weight basis) in inoculated soils was more than the respective uninoculated soils. In the later samplings, however, i.e. at 4, 5, 6 months and one-year sampling, the root/shoot ratio (on a fresh and dry weight basis) was observed to be less in the inoculated soils/seedlings than the uninoculated soils, by the proposed hypothesis. In the inoculated soils the root/shoot ratio was observed to be maximum in wasteland soil followed by forest soil and the mixture of soils at 4, 5, 6 months and one-year sampling. Inverse root and shoot ratio, i.e. ratio between shoot/root has been recorded by Molina (1982) in Western hemlock, douglas fir, sitka spruce, and by Marx et al. (1976) in loblolly and Virginia pine and Kumar (1989) in Pinus gerardiana.

The results for root collar diameter and seedling volume indicate that inoculated seedlings attained greater root collar diameter and seedling volume than uninoculated seedlings at 4, 5, 6 months, and one-year sampling stages. For the three types of inoculated soils, the mean values for root collar diameter and seedling volume were maximum in a mixture of soils followed by forest soil and wasteland soil at all sampling stages. But root collar diameter in all inoculated soils and seedling volume in forest soil and wasteland soil was not significantly higher than their respective uninoculated soils. Marx and Bryan (1975); Marx and Artman (1978), Ruehle et al. (1981b), and Holusa et al. (2015) also recorded higher collar diameter in inoculated seedlings of loblolly pine and $P$. halepensis but Molina (1979) observed no significant difference in root collar diameter of inoculated douglas fir and lodge pole pine seedlings.

Root system in $C$. deodara is heterozoic, i.e. distinguished into long and short roots. The inoculated and uninoculated (with natural inoculum) long roots were observed to be pointed and white to yellow at the tip morphologically. Anatomically the fungus was seen to colonize the surface of long roots before entering the cortical region. A typical Hartig 
net was present in long roots of 2-4-month-old seedlings conforming the ectomycorrhizal type. The long roots in nature were also observed to be ectomycorrhizal. However, conflicting views on mycorrhiza of long roots have been reported by Bakshi et al. (1968).

The presence of Hartig net in the cortices of normal long roots has been reported by many researchers (Laing, 1932; Moller, 1947; Robertson, 1954; Mausi, 1926). Harley and Smith (1983) opined that ectomycorrhizal infection of the host is a permanent feature of the fungus in or on long roots i.e. associated with the permanent root axis often acts as a reservoir of infectivity ensuring that most of the new laterals become infected.

Mycorrhiza formation on short roots of C. deodara begins when the seedlings are about $2 \frac{1}{2}$ months old. There are no significant differences in the morphology of short roots in two treatments and three types of soils. The roots were monopodial or branched racemosely, light coloured initially and uniformly dark brown at 4-5-month age. Bakshi and Thapar (1966) opined that the colour of fungal symbiont was constant for a species and that the colour changes with the age of the roots.

Morpho-anatomical observations revealed the absence of root hairs on the mycorrhizal short roots of $C$. deodara. Thomson et al. (1989) also reported a gradual loss of root hairs in Picea mariana as the mantle develops. Anatomically it was ectendomycorrhiza in the uninoculated seedlings and ectomycorrhiza in inoculated seedlings.

These observations are also supported by Mikola (1965) who reported that in uninoculated seedlings, the mycorrhiza was of ectendotrophic type and in inoculated seedlings, it was of ectotrophic type. He had also made similar observations for mycorrhizae of nursery plants and those of natural forest stand.

\section{CONCLUSION}

It can be concluded from the studies on growth and development, that artificial inoculation of $C$. deodara seedlings produced better seedling growth and development. Artificial inoculation with a specific mycorrhizal fungus is, therefore, doubtlessly beneficial. Further, it is also clear from the results obtained that if wasteland soil and natural zone soil are mixed in 1:1 ratio, it can produce better growth and development of $C$. deodara seedlings. A mixture of soils, whether inoculated or uninoculated, gives better results than other types of soil. The inoculated seedlings acquire the transplanting height of $25-30 \mathrm{~cm}$ in six-month time, which is almost three times that achieved with natural inoculum. This suggests a great economic benefit in terms of time, energy, and money.

\section{ACKNOWLEDGEMENTS}

The authors are grateful to the authorities of the Department of Biosciences, H.P. University, Summer Hill, Shimla and various granting agencies (DST, MoEF, UGC) for providing necessary laboratory facilities and funding for this research work.

\section{REFERENCES}

Arteaga-León, C., Pérez-Moreno, J., Espinosa-Victoria, D., José Almaraz-Suárez, J., Silva-Rojas, H. and Delgado-Alvarado, A. 2018. Ectomycorrhizal inoculation with edible fungi increases plant growth and nutrient contents of Pinus ayacahuite. Revista Mexicana de Biodiversidad 89 (4): 1089-1099.

Asif, M., Lone, S., Lone, F.A. and Hamid, A. 2013. Field performance of blue pine (Pinus wallichiana) seedlings inoculated with selected species of bioinoculants under nursery conditions. Int. J. Pharm. Bio. Sci. 4 (1): 632-640.

Bakshi, B.K. and Thapar, H.S. 1966. Studies on mycorrhiza of chirpine (Pinus roxburghii). Proc. Nat. Inst. Sci. India 32: 6-20.

Bakshi, B.K., Thapar, H.S. and Singh, B. 1968. Mycorrhiza in blue pine, spruce and deodar. Proc. Nat. Inst. Sci. India 84:27-34.

Berry, C.R. 1982. Dried sewage sludge improves growth of pines in the Tennessee copper Basin. Reclam. and Reveg. Res. 1:195-201.

Bowen, G.D. 1965 Mycorrhiza inoculation in forestry practices. Aust. For. 29: 231-237.

Bowen, G.D., Skinner, M.F. and Bevege, D.I. 1974. Zinc uptake by mycorrhizal and uninfected roots of Pinus radiata and Araucana cunninghamii. Soil Biol. Biochem. 6: 141-144.

Dickie, I.A., Koide, R.T. and Steiner, K.C. 2002. Influences of established trees on mycorrhizas, nutrition, and growth of Quercus rubra seedlings. Ecol. Monogr. 72: 505-521.

Gobi, F. 1975. Erfahrungen beider Anzucht von Myeorrhiza Impfmaterial. Centralbl. Ges, forstw. 92: 227-237.

Graham, J.H. and Linderman, R.G. 1980. Ethlylene production by ectomycorrhizal fungi, Fusarium oxysporum and by aseptically synthesized ectomycorrhiza and Fusarium infected douglas fir roots. Can. J. Microbiol. 26: 1340-1347.

Harley, J.L. 1959. The Biology of Mycorrhiza. Leonard Hill, London.

Harley, J.L. and Smith, S.E. 1983. Mycorrhizal Symbiosis. Academic press, London.

Hatch, A.B. 1937. The physical basis of mycotrophy in the genus Pinus. Black Rock For. Bull. 6.

Herrera, R., Merida, T., Stark, M. and Jordan, C.F. 1978. Direct phosphorus transfer from leaf litter to roots. Maturwissenschaften 65:208-209.

Holusa, J., Peskova, V. and Lorenc, F. 2015. The impact of artificial mycorrhizal inoculation on the growth of common oak seedlings and development of mycorrhiza: Inoculation may not positively affect growth of seedlings. Periodicum Biologorum 117 
(4): 519-526

Hung, L.L. and Molina, R. 1986. Use of the ectomycorhizal fungus Laccaria laccata in forestry III. Effects of commercially produced inoculum on containergrown dougla's fir and ponderosa pine seedlings. Can J. For. Res. 16: 802-806.

Hung, L.L., Chien, C.Y. and Ying, S.L. 1982. Effects of soil fumigation and mycorrhizal inoculation on ectomycorrhizal formation and growth of Taiwan red pine containerized seedlings. Quar. J. Chinese Forestry 15: 13-19.

Johansen, D.A. 1940. Plant Microtechnique. Tata McGrawHill Publishing company, New Delhi.

Kaewgrajang, T., Sakolrak, B., and Sangwanit, U. 2019. Growth response of Dipterocarpus tuberculatus and Shorea roxburghii seedlings to Astraeus odoratus. Environment and Natural Resource Journal 17 (3): 80-88.

Kumar, Jitender and Atri, N.S. 2017. Studies on Mycorrhiza: An appraisal. Bot. Rev. Https://doi.org/10.1007/ s12229-017-9196-z.

Kumar, S. 1989. Studies on mycorrhiza of Picea smithiana and Pinus gerardiana. Ph.D. Thesis. H.P. University, Shimla.

Laing, E.V. 1932. Tree roots: Their action and development. Trans. R. Scott. Arboric Soc. 37: 6-12.

Marx, D.H. 1980. Ectomycorrhizal fungus inoculation-A tool for improving forestation practices. In: Mycorrhizal Research (Ed.: P. Mikola), pp 13-71. Oxford University Press.

Marx, D.H. and Artman, J.D. 1978. Growth and ectomycorrhizal development of loblolly pine seedlings in nursery soil infested with Pisolithus tinctorius and Thelephora terrestris in Virginia. USDA Forest Serv. Res. Note SE 256.

Marx, D.H. and Bryan, W.C. 1970. Pure culture synthesis of ectomycorrhizae of Thelephora terrestris and Pisolithus tinctorius on different conifer hosts. Can. J. Bot. 48: 639-643.

Marx, D.H. and Bryan, W.C. 1975. Growth and ectomycorrhizal development of loblolly pine seedlings in fumigated soil infested with the fungal symbiont Pisolithus tinctorius. For. Sci. 22: 245254.

Marx, D.H. and Cordell, C.E. 1989. The use of specific ectomycorrhizas to improve artificial forestation practices. In: Biotechnology of fungi for improving plant growth (Eds.: Whipps, J.W. and Lumsden, R.D.). Cambridge University Press, Cambridge., pp 1-25.

Marx, D.H. Bryan, W.C. and Cordell, C.E. 1976. Growth and ectomycorrhizal development of pine seedlings in nursery soils infested with the fungal symbiont
Pisolithus tinctorius. For. Sci. 22: 91-100.

Marx, D.H., Bryan, W.C. and Cordell, C.E. 1977. Survival and growth of pine seedlings with Pisolithus ectomycorrhizae after two years on reforestation sites in North Carolina and Florida. For. Sci. 23:367373.

Marx, D.H., Bryan, W.C. and Davey, C.W. 1970. Influence of temperature on aseptic synthesis of ectomycorrhizae by Thelephora terrestris and Pisolithus tinctorius on loblolly pine. For. Sci. 16: 424-431.

Marx, D.H., Ruehle, J.L. and Cordell, C.E. 1991. Methods for studying nursery response of trees to specific ectomycorrhiza. In: Methods in microbiology (Eds.: Norris, J.R., Read, D.J. and Varma, A.K.). pp-383411. Academic Press, London.

Mausi, K. 1926. A study of mycorrhiza of Abies firma with special reference to its mycorrhizal fungus Cantharellus floccosus. Mem. Coll Sci. Kyoto. Imp.Univ. B. 2: 85-92.

Mejestik, V.K. and Krause, H.H. 1973. Uptake of 32p by Pinus radiata inoculated with Suillus luteus and Cenococcum graniforme from different sources of available phosphate. New Phytol. 72:137-140.

Mejstrik, V.K. 1970. The uptake of 32p by different kinds of mycorrhizas of Pinus. New Phytol. 69:295-298.

Melin, E.1953. Physiology of mycorrhizal relations in plants Ann. Rev. Plant Physiol. 4: 325-346.

Mikola, P. 1965. Studies on the ectendotrophic mycorrhiza of pine. Acta Forest. Fenn. 79: 1-56.

Mikola, P. 1970. Mycorrhizal inoculation in afforestation. Inst. Rev.For. Res. 3:123-196.

Mikola, P. 1973. Application of mycorrhizal symbiosis in forestry practices. In: Ectomycorrhizae: Their Ecology and Physiology (Eds.: Marks, G.C. and Kozlowski, T.T.), pp 383-411. Academic Press, New York

Molina, R. 1977. Ectomycorrhizal fungi and forestry practices. In: Mushrooms and Man, an Interdisciplinary Approach to Mycology. (Ed.:Walters, T.), pp 147- 161. USDA Forest Service.

Molina, R. 1979. Pure culture synthesis and host specificity of Red Alder mycorrhiza. Can. J. Bot. 57: 1223-1225.

Molina, R. 1982. Use of the ectomycorrhizal fungus Laccaria laccata in forestry I. Consistency between isolates in effective colonisation of containerized conifer seedlings. Can. J. For. Res. 12: 469-473.

Moller, C. 1947. Mycorrhizae and nitrogen assimilation. Forstt. Forsoksr. Dann. 19: 105- 208.

Moser, M. 1958. Der Einfluss tiefer Temperaturen auf das Wachstum und die Lebenstadigkeit hoherer Pilze mit spezieller Berucksichtigung von Mykorrhizapilzen. 
Sydowia 12: 386-399.

Park, J.Y. 1971. Preparation of mycorrhizal grain spawn and its practical utility in artificial inoculation. In: Mycorrhizae (Ed.: Hacskaylo, E.), pp 239-240. Washington, DC.

Parladé, J., Luque, J., Pera, J. and Rincón, A.M. 2004. Field performance of Pinus pinea and P. halepensis seedlings inoculated with Rhizopogon spp. and outplanted in formerly arable land. Ann. For. Sci., 61(6): 507-514.

Riffle, J.W. and Tinus, R.W. 1982. Ectomycorrhizal characteristics, growth, and survival of artificially inoculated ponderosa and Scots pine in a greenhouse and plantation For. Sci. 28: 646-660.

Rincon, A., Alvarez, I.F. and Pera, J. 2001. Inoculation of containerized Pinus pinea L. seedlings with seven ectomycorrhizal fungi. Mycorrhiza 11: 265-271.

Robertson, N.F. 1954. Studies on the mycorrhiza of Pinus sylvestris. New Phytol. 53:253-283.

Ruehle, J.L., Marx, D.H. and Abourouh, M. 1981a. Development of $P$. tinctorius and Thelephora terrestris ectomycorrhizae on seedlings of coniferous trees important to Morocco. Ann.de la Re cherche Forestiere. Nu Maroc. 21: 281-296.

Ruehle, J.L., Marx, D.H., Barnet, J.P. and Pawuk, W.H. 1981b. Survival and growth of container-grown and bare-root shortleaf pine seedlings with Pisolithus and Thelephora ectomycorrhizae. South. J. of Appl. For. 1: 20-24.

Ruehle, J.L.1980. Growth of containerized loblolly pine with specific ectomycorrhizae after 2 years on an amended borrow pit. Reclamation Review 3: 95 101.

Singh, L. 1992. Studies on mycorrhizal relationship of Trappeinda himalayensis and Cedrus deodara, $\mathrm{Ph}$. D. thesis, Himachal Pradesh University, Shimla.

Singh, L., Tapwal, A., Thakur, J.S. and Lakhanpal, T.N. 2020. Studies on the nutritional requirement and in vitro synthesis of mycorrhiza of Cedrus deodara with hypogeous edible Rhizopogon himalayensis. Kavaka 54: 24-29.

Slankis, V. 1973. Hormonal relationships in mycorrhizal development. In: Ectomycorrhizae: Their ecology and physiology (Eds.: Marks, G.C. and Kozlowski,T.T.), pp 231-298. Academic Press. New York.

Stoller, B.B. 1962. Some practical aspects of making mushroom spawn. Mush. Sci. 5: 170-184.

Tackacs, E.A. 1967. Produccion de cultivos puros de hongos micorrizogenos enel centro macional de Investigaciones Agropecuarias, Castelar. Idia Supl. For. 4: 83-87.

Theodorou, C. and Bowen, G.D. 1970. Mycorrhizal responses of radiata pine in experiments with different fungi. Aust. For. 34: 183-191.

Thomson, J., Melville, L.H. and Peterson, R.L. 1989. Interactions between the ectomycorrhizal fungus Pisolithus tinctorius and root hairs of Picea marina (Pinaceae). Am.J. Bot., 76: 632-636.

Trappe, J.M. 1977. Selection of fungi for ectomycorrhizal inoculation in nurseries. Ann.Rev. Phytopathology 75: 203-222.

Valdes, M. 1986. Survival and growth of pines with specific ectomycorrhizae after three years on a highly eroded site. Can. J. Bot. 64: 885-888.

Vazzo, J.H. and Hacskaylo, E. 1971. Inoculation of Pinus caribaes with ectomycorrhizal fungi in Puerto Rico. For Sci. 17: 239-245.

Yang, C.S. and Wilcox, H.E. 1984. Technique for observation of mycorrhizal development under monoxenic condition. Can. J. Bot. 62:251-254.

Zak, B.1971. Characterization and identification of douglas fir mycorrhizae In: Mycorrhizae (Ed.: Hacskaylo, E.E.). Washington, D.C. pp, 38-53. 